\title{
Magnesium diboride on inner wall of copper tube: A test case for superconducting radio frequency cavities
}

\author{
Wenura K. Withanage, ${ }^{1, *}$ N. H. Lee, ${ }^{1}$ Sashank V. Penmatsa, ${ }^{1}$ \\ M. A. Wolak, ${ }^{1, \dagger}$ A. Nassiri, ${ }^{2,3}$ and X. X. $\mathrm{Xi}^{1}$ \\ ${ }^{1}$ Department of Physics, Temple University, Philadelphia, Pennsylvania 19122, USA \\ ${ }^{2}$ Argonne National Laboratory, Argonne, Illinois 60439, USA \\ ${ }^{3}$ College of Engineering, Michigan State University, East Lansing, Michigan 48824, USA
}

(Received 18 August 2017; published 31 October 2017)

\begin{abstract}
Superconductor magnesium diboride is considered one of the viable materials to substitute bulk niobium for superconducting radio frequency cavities. Utilizing a $\mathrm{MgB}_{2}$ coating on the inner wall of a copper cavity will allow operation at higher temperatures $(20-25 \mathrm{~K})$ than $\mathrm{Nb}$ cavities due to the high transition temperature of $\mathrm{MgB}_{2}(39 \mathrm{~K})$ and the high thermal conductivity of $\mathrm{Cu}$. In this paper, we present results of $\mathrm{MgB}_{2}$ coating on $\mathrm{Cu}$ tubes with similar dimensions to a $3 \mathrm{GHz}$ cavity, as the first step towards coating the actual cavity, using the hybrid physical chemical vapor deposition technique. The results show successful coating of a uniform $\mathrm{MgB}_{2}$ layer on the inner wall of the $\mathrm{Cu}$ tubes with $T_{c}$ as high as $37 \mathrm{~K}$.
\end{abstract}

DOI: 10.1103/PhysRevAccelBeams.20.102002

\section{INTRODUCTION}

Bulk $\mathrm{Nb}$ superconducting radio frequency (SRF) cavities are a well-researched technology and have been successfully deployed in superconducting particle accelerators. However, Nb SRF cavities are quickly approaching their theoretical limits in terms of the highest achievable accelerating gradient $\left(E_{\text {acc }}\right)$, which is ultimately limited by the thermodynamic critical field $\left(H_{c}\right)$ [1]. Nb has a transition temperature, $T_{c}$, of $9.25 \mathrm{~K}$, thus Nb-based SRF cavities typically operate at a temperature of $2 \mathrm{~K}$, which requires pumping liquid $\mathrm{He}$ and complex refrigeration, thereby adding substantial cost. Due to these drawbacks of bulk $\mathrm{Nb}$ SRF cavities, the search for new materials with higher $T_{c}$ and better rf performance has been a focus of SRF research. $\mathrm{MgB}_{2}$ is one of the materials of interest for SRF cavities. It possesses appealing superconducting properties for SRF applications, including high $T_{c}$ of $39 \mathrm{~K}$ [2], low residual resistivity [3], high thermodynamic critical field $H_{c}$ [4], and absence of weak links at grain boundaries [5]. With these properties, theoretical calculations have predicted a high quality factor $(Q)$ and high $E_{\text {acc }}$ for $\mathrm{MgB}_{2}$ coated SRF cavities $[4,6]$. In addition, the high $T_{c}$ of $\mathrm{MgB}_{2}$ will allow $\mathrm{MgB}_{2}$ coated SRF cavities to work at higher temperatures above $20 \mathrm{~K} . \mathrm{MgB}_{2}$ coated $\mathrm{Cu}$ cavities will have an added advantage from the high thermal

\footnotetext{
*tue76590@temple.edu

Present address: Sandia National Laboratories, Albuquerque, NM 87185, USA.

Published by the American Physical Society under the terms of the Creative Commons Attribution 4.0 International license. Further distribution of this work must maintain attribution to the author(s) and the published article's title, journal citation, and DOI.
}

conductivity of $\mathrm{Cu}$, which will ensure the enhanced heat transfer from the $\mathrm{MgB}_{2}$ layer, eventually improving the cavity's resistance to "quenching." This has been observed in $\mathrm{Nb}$ coated $\mathrm{Cu}$ cavities [7]. $\mathrm{MgB}_{2}$ coated $\mathrm{Cu}$ cavities working at $20-25 \mathrm{~K}$ will eliminate the need for liquid $\mathrm{He}$ refrigeration [8].

We have grown $\mathrm{MgB}_{2}$ films on two-inch $\mathrm{Cu}$ disks previously using hybrid physical chemical vapor deposition (HPCVD) and tested their superconducting properties at dc and $\mathrm{rf}$ frequencies. Growth of $\mathrm{MgB}_{2}$ on $\mathrm{Cu}$ is challenging because $\mathrm{Mg}$ and $\mathrm{Cu}$ form alloys at elevated temperatures. This problem has been solved by lowering the deposition temperature to around $470{ }^{\circ} \mathrm{C}$ [8], where the formation of $\mathrm{Mg}_{2} \mathrm{Cu}$ promotes the growth of $\mathrm{MgB}_{2}[9,10]$. The films showed high $T_{c}$, high critical current density $\left(J_{c}\right)$ and high $Q$ when measured in a cryogenic high- $Q$ hemispheric cavity at $11.4 \mathrm{GHz}$ [8]. Coating of stainless steel dummy 6 and $3 \mathrm{GHz}$ SRF cavities with $\mathrm{MgB}_{2}$ using HPCVD has been previously demonstrated $[11,12]$. In this paper, we discuss coating of the inner wall of $\mathrm{Cu}$ tubes, which have similar dimensions to a $3 \mathrm{GHz}$ cavity beam tube using a modified HPCVD setup. Deposition conditions for uniform coating of a $\mathrm{MgB}_{2}$ layer with good superconducting properties have been investigated. The results are a successful first step towards the coating of the actual $\mathrm{Cu}$ cavity for testing at $3 \mathrm{GHz}$.

\section{EXPERIMENTAL DETAILS}

To test the deposition conditions for coating the inner wall of $3 \mathrm{GHz} \mathrm{Cu}$ cavities, $\mathrm{Cu}$ tubes with dimensions similar to the $3 \mathrm{GHz}$ rf cavity beam tubes were coated. The unpolished commercial $\mathrm{Cu}$ tubes (not oxygen free) have an outer diameter of 1.675 inches, an inner diameter of 1.495 inches, and a length of $\sim 8.5$ inches. The $\mathrm{Cu}$ tubes 
were split in two for the ease of cleaning before the deposition and characterization after the deposition. They were cleaned in an ultrasonic bath in soap (micro90), the $\mathrm{Cu}$ cleaning solution Citranox, and de-ionized water in succession before they were dried with $\mathrm{N}_{2}$ gas. The two halves were assembled to form a tube during the deposition.

A photo of the HPCVD system for cavity coating is shown in Fig. 1(a) and schematics of the system with the $\mathrm{Cu}$ tube at the start and end positions are shown in Figs. 1(b) and 1(c), respectively. The HPCVD system consists of a thermally insulated gas tube from the top to supply the $5 \% \mathrm{~B}_{2} \mathrm{H}_{6}$ in $\mathrm{H}_{2}$ gas mixture and the $\mathrm{H}_{2}$ carrier gas, a tubular $\mathrm{Mg}$ oven from the bottom of the vacuum chamber as the $\mathrm{Mg}$ source, and a 5-inch diameter tubular heater that heats the entire assembly. The tubular heater has two separate parts, with a removable front half, which allows for loading/unloading of the $\mathrm{Cu}$ tube or cavity into the system. There is a $\sim 3.5$-inch gap between the top of the $\mathrm{Mg}$ oven and the opening of the $\mathrm{B}_{2} \mathrm{H}_{6}$ gas line where $\mathrm{B}$ and $\mathrm{Mg}$ react to form $\mathrm{MgB}_{2}$. The $\mathrm{B}_{2} \mathrm{H}_{6}$ gas line is enclosed in a stainless-steel tube, which can rotate and move vertically ( $\mathrm{Z}$ direction), and serve as the mounting mechanism for the $\mathrm{Cu}$ tube or cavity to be coated. The photo in Fig. 1(a) shows the HPCVD setup with a $\mathrm{Cu}$ tube loaded while the front circular heater is removed.

At the start of the deposition, the $\mathrm{Cu}$ tube was at the lowest position such that the reaction zone was at the top of the tube [see Fig. 1(b)]. A carrier gas of 5 Torr $\mathrm{H}_{2}$ was used during the deposition. The temperature of the tubular heater was maintained at around $660^{\circ} \mathrm{C}$ and the temperature of the $\mathrm{Mg}$ oven was around $600^{\circ} \mathrm{C}$. As discussed in Ref. [8], a $\mathrm{Mg}-\mathrm{Cu}$ alloy formed on the $\mathrm{Cu}$ surface at this stage before the $\mathrm{B}_{2} \mathrm{H}_{6}$ gas mixture was introduced, which initiated the $\mathrm{MgB}_{2}$ deposition. The flow rate of the $5 \% \mathrm{~B}_{2} \mathrm{H}_{6}$ in $\mathrm{H}_{2}$ gas mixture was 20 standard cubic centimeters per minute (sccm). The $\mathrm{Cu}$ tube was then moved upward with a speed suited for the intended thickness of the $\mathrm{MgB}_{2}$ coating. In this configuration, the $\mathrm{MgB}_{2}$ deposition starts from the top and progresses to the bottom. The end position of the system is shown in Fig. 1(c). Throughout the deposition process, the $\mathrm{Cu}$ tube was rotated for uniform coating. For $\sim 850 \mathrm{~nm}$ thick $\mathrm{MgB}_{2}$, the $Z$ motion speed was $\sim 0.33$ inch per minute and the deposition time was around 30 minutes.

After the deposition, small swatches of the $\mathrm{MgB}_{2}$ coated tube from different locations on the $\mathrm{Cu}$ tube were cut out for characterization. Surface morphology of the swatches was studied with scanning electron microscope (SEM) using a 470 FEI Quanta FEG system. A quantum design physical properties measurement system was used to determine $T_{c}$ of the samples by magnetic moment $(m)$ versus temperature (T) measurements in a 50 Oe magnetic field. For crosssectional studies of the samples, focused ion beam (FIB) was used to mill holes in the swatches using an FEI Strata DB235 dual beam system. The thickness of the $\mathrm{MgB}_{2}$ layer on the cross-sectional sample was measured by SEM, and the deposition rate thus obtained in terms of the $Z$ motion speed was used to determine the thickness of other samples. Two coated tube samples with different $\mathrm{MgB}_{2}$ (a)

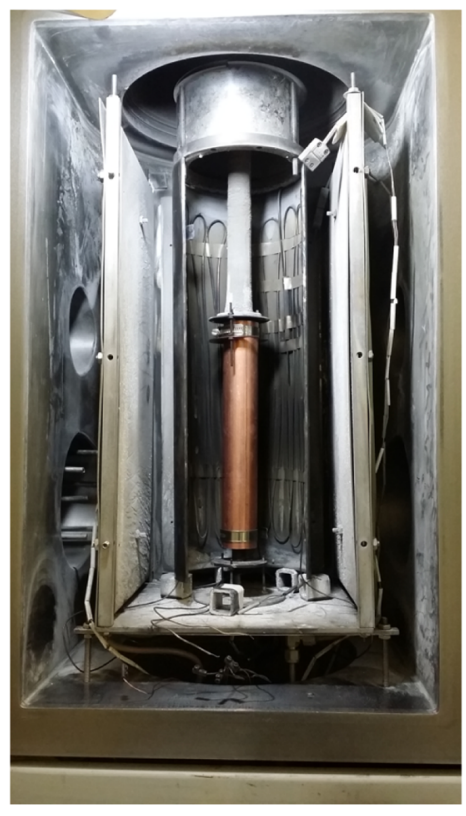

(b)

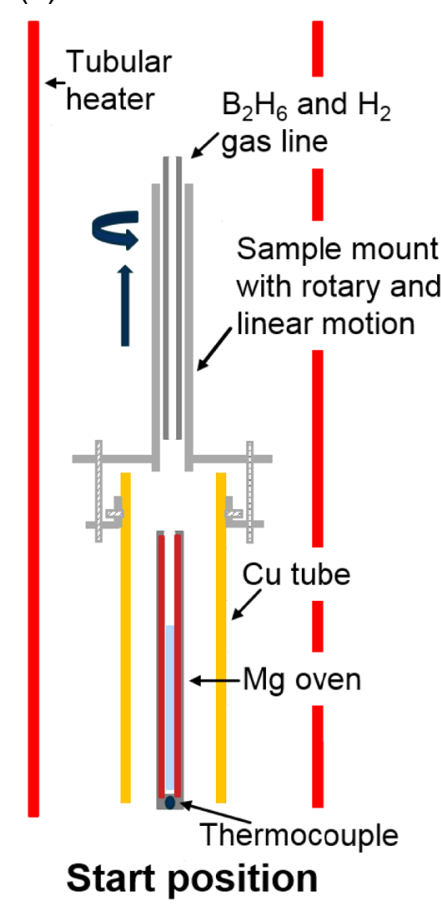

(c)

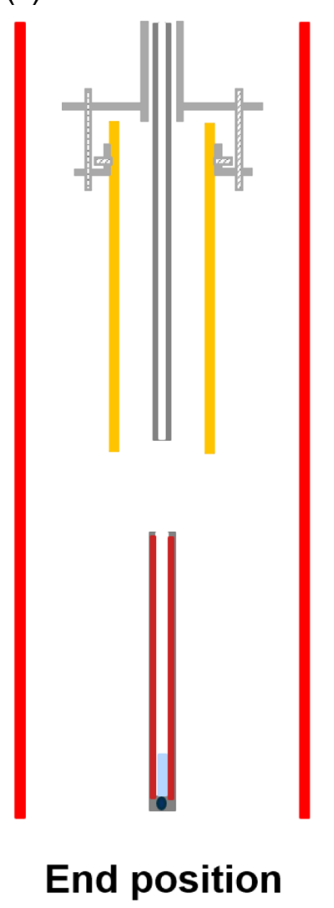

FIG. 1. (a) A photo of the HPCVD system for cavity coating is shown here. (b) The schematic of the system with the Cu tube at the starting position. (c) Schematic of the system with the $\mathrm{Cu}$ tube at the end position. 
layer thicknesses were characterized by surface morphology and $T_{c}$ measurements.

\section{RESULTS AND DISCUSSIONS}

Figure 2(a) shows a photo of the inside wall of a splithalf $\mathrm{Cu}$ tube after the coating of a $\sim 550 \mathrm{~nm} \mathrm{MgB}_{2}$ film. A range of colors are seen along the length of the tube, which is divided into six regions. Region 1 appears metallicthere is either no coating at all or no $\mathrm{MgB}_{2}$ coating in this region. From region 2 to region 5 , the color gradually changes from dark greenish to purplish. Based on our prior experience, the former is indicative of $\mathrm{Mg}$ deficiency and the latter is characteristic of pure $\mathrm{MgB}_{2}$ films. Irregular light stripes are seen in region 4.

In Figs. 2(b)-2(e), SEM images of the samples from

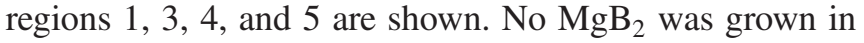
region 1 and the morphology reflects properties of a bare $\mathrm{Cu}$ surface with marks of machining. With the gas flow from top to bottom, the top region of the tube experiences gas dynamics different from deep inside the tube, which could result in no coating being present in that region. From region 3 to region 5, well-connected $\mathrm{MgB}_{2}$ grains can be seen with increasing grain sizes. The variation in the grain size may be the result of changing deposition temperature (cooler at the top than at the bottom of the tube). Cracks in the coating are also observed. With a large mismatch of thermal expansion coefficients $\left(16.5 \times 10^{-6} / \mathrm{K}\right.$ for $\mathrm{Cu}$ and
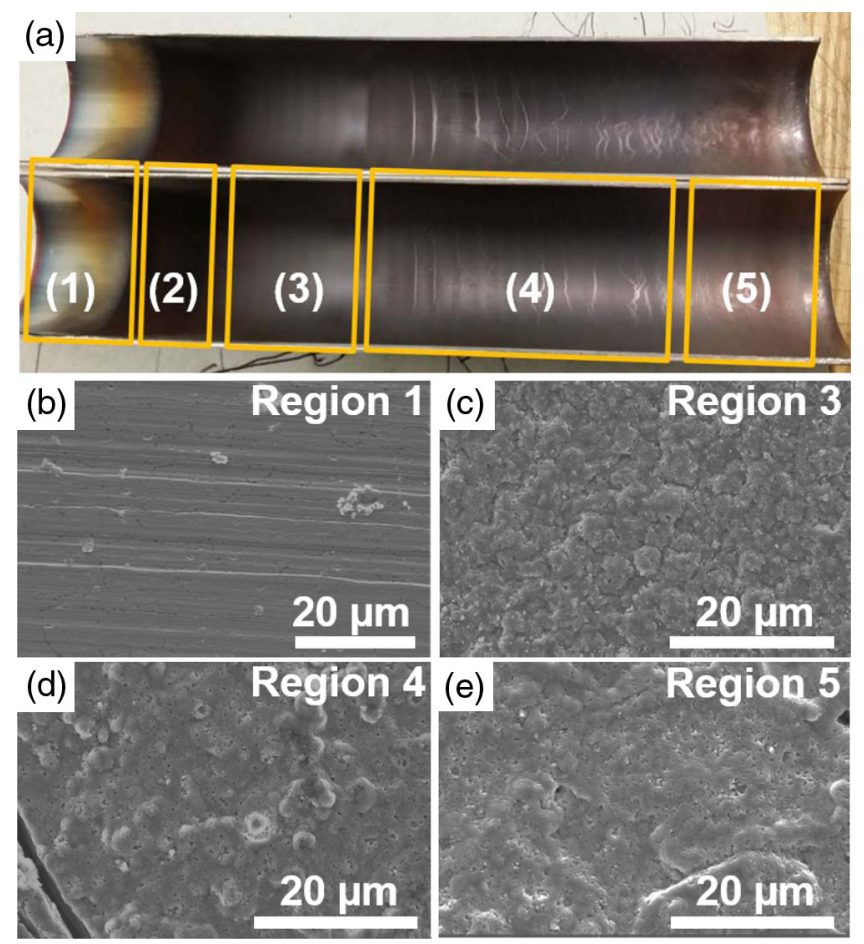

FIG. 2. (a) A photo of $\sim 550 \mathrm{~nm}$ thick $\mathrm{MgB}_{2}$ coated $\mathrm{Cu}$ tube halves. (b)-(e) SEM images of $\mathrm{MgB}_{2}$ film surface on $\mathrm{Cu}$ samples cut out from regions 1, 3, 4 and 5, respectively.
$5.4 \times 10^{-6} / \mathrm{K}$ for $\mathrm{MgB}_{2}$ near room temperature [13]), cracks in the $\mathrm{MgB}_{2}$ coating on $\mathrm{Cu}$ are expected, as the sample experiences contraction when it is cooled from the deposition temperature to room temperature.

Figure 3 shows the zero-field cooled $m$ vs $T$ curves for the samples from region 2 to region 5. All samples showed superconducting transition with $T_{c}$ ranging from $35 \mathrm{~K}$ for region 2 to $37.5 \mathrm{~K}$ for region 5 .

In Fig. 4(a), a photo of a sample coated with a $\sim 850 \mathrm{~nm}$ $\mathrm{MgB}_{2}$ film is shown. Again, the top region of the tube is not coated. The coating from region 2 to region 6 appears much more uniform than in the thinner $\sim 550 \mathrm{~nm}$ sample, particularly in regions 3 and 4 . Also absent are the irregular stripes in the thinner sample, although regular stripes perpendicular to the tube axis can be seen, possibly due to the variation of the deposition rate with $Z$ motion. The SEM images of the surface morphology for regions 2, 3, 4 and 5 are shown in Figs. 4(b)-4(e), respectively. Again, well-connected $\mathrm{MgB}_{2}$ grains are seen with increasing grain sizes from the top to the bottom. It should be noted that no cracks are observed in the $\sim 850 \mathrm{~nm}$ sample, although region 5 shows pinholes between the large grains. It appears that the cracks seen in the thinner sample no longer exist in the thicker sample. Regular periodic darker lines can be seen in regions 4 and 5 in Fig. 4(a). We believe that these regular periodic lines are a result of uneven coating area overlap during rotation and $Z$ motion of the $\mathrm{Cu}$ tube. Misalignment between the $\mathrm{Cu}$ tube, $\mathrm{Mg}$ oven and gas line can cause uneven coating.

Cross-sectional samples of the $\sim 850 \mathrm{~nm}$ coating on $\mathrm{Cu}$ were measured by SEM and the images are shown in Fig. 5. Figures 5(a), 5(b) and 5(c) are for regions 2, 3 and 6, respectively. A thick platinum layer was deposited on top of the sample prior to the FIB milling to protect the $\mathrm{MgB}_{2}$ layer. The images were taken at a $53.5^{\circ}$ angle, which was

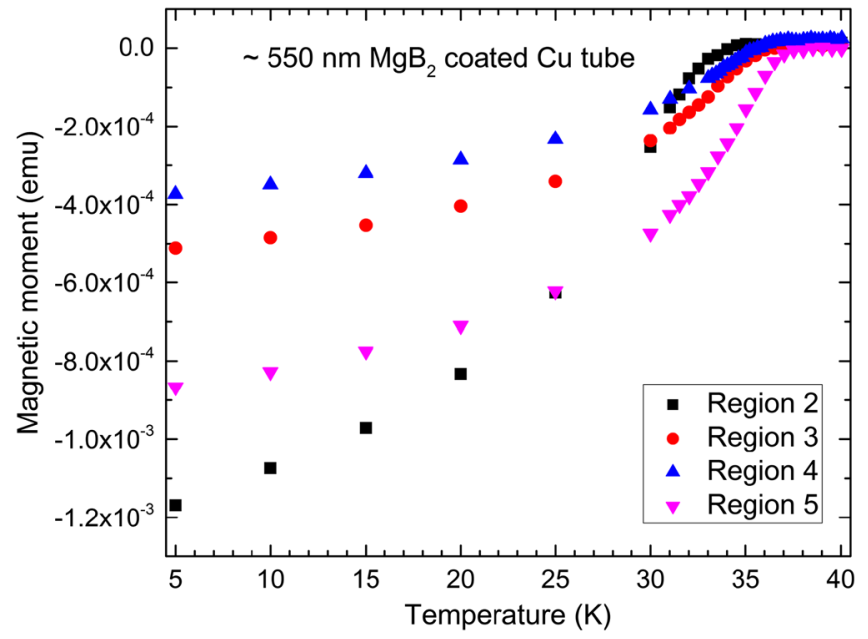

FIG. 3. Magnetic moment vs temperature curves of samples from regions 2, 3, 4 and 5 of a $\sim 550 \mathrm{~nm}$ thick $\mathrm{MgB}_{2}$ coated $\mathrm{Cu}$ tube. 

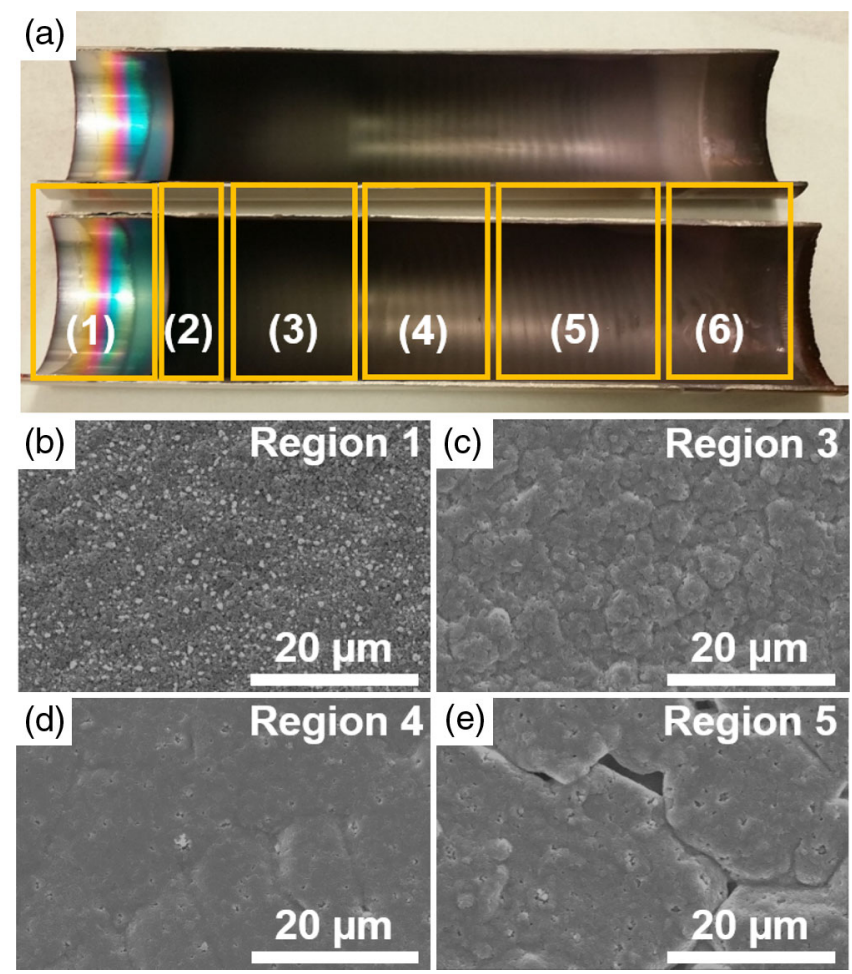

FIG. 4. (a) Photo of $\sim 850 \mathrm{~nm}$ thick $\mathrm{MgB}_{2}$ coated $\mathrm{Cu}$ tube halves. (b)-(e) SEM images of $\mathrm{MgB}_{2}$ film surface on $\mathrm{Cu}$ samples cut out from regions 2, 3, 4 and 5, respectively. accounted for in the thickness calculation. The crosssectional image from region 2 [Fig. 5(a)] shows an $\mathrm{MgB}_{2}$ layer intruded by a large number of bright flecks. According to our previous work of $\mathrm{MgB}_{2}$ coating on $\mathrm{Cu}$ disks [8], these flecks are a $\mathrm{Mg}$-Cu alloy appearing in areas where $\mathrm{Mg}$ vapor is insufficient during the deposition. It confirms that the top of the tube suffers from $\mathrm{Mg}$ deficiency due to the specific gas dynamics in the area. Also visible in Fig. 5(a) is the $\mathrm{Mg}-\mathrm{Cu}$ alloy layer under the $\mathrm{MgB}_{2}$ film, similar to that observed in $\mathrm{MgB}_{2}$ coating on the $\mathrm{Cu}$ disk. This layer is not distinguishable in the images for region 3 [Fig. 5(b)] and region 6 [Fig. 5(c)], most likely because the boundary of the alloy layer and the $\mathrm{Cu}$ substrate is out of view. Figures 5(b) and 5(c) show dense and conformal growth of the $\mathrm{MgB}_{2}$ layer with occasional voids near the $\mathrm{MgB}_{2} / \mathrm{Cu}$ interface. The blowup of a void in Fig. 5(b) is shown in Fig. 5(d). It is clearly seen that it occurs at a sharp edge on the unpolished $\mathrm{Cu}$ surface. It is most likely associated with cracks on thinner $\mathrm{MgB}_{2}$ coating as seen in Fig. 2, which is then sealed when the film thickness increases. Using these cross-sectional images, the film thickness was determined to be $\sim 850 \mathrm{~nm}$ for this sample.

Figure 6 shows the zero-field cooled $m$ vs $T$ curves for the $\sim 850 \mathrm{~nm}$ samples from various regions. All the samples showed superconducting transition $\sim 37 \mathrm{~K}$. It should be noted that the samples used in the measurement
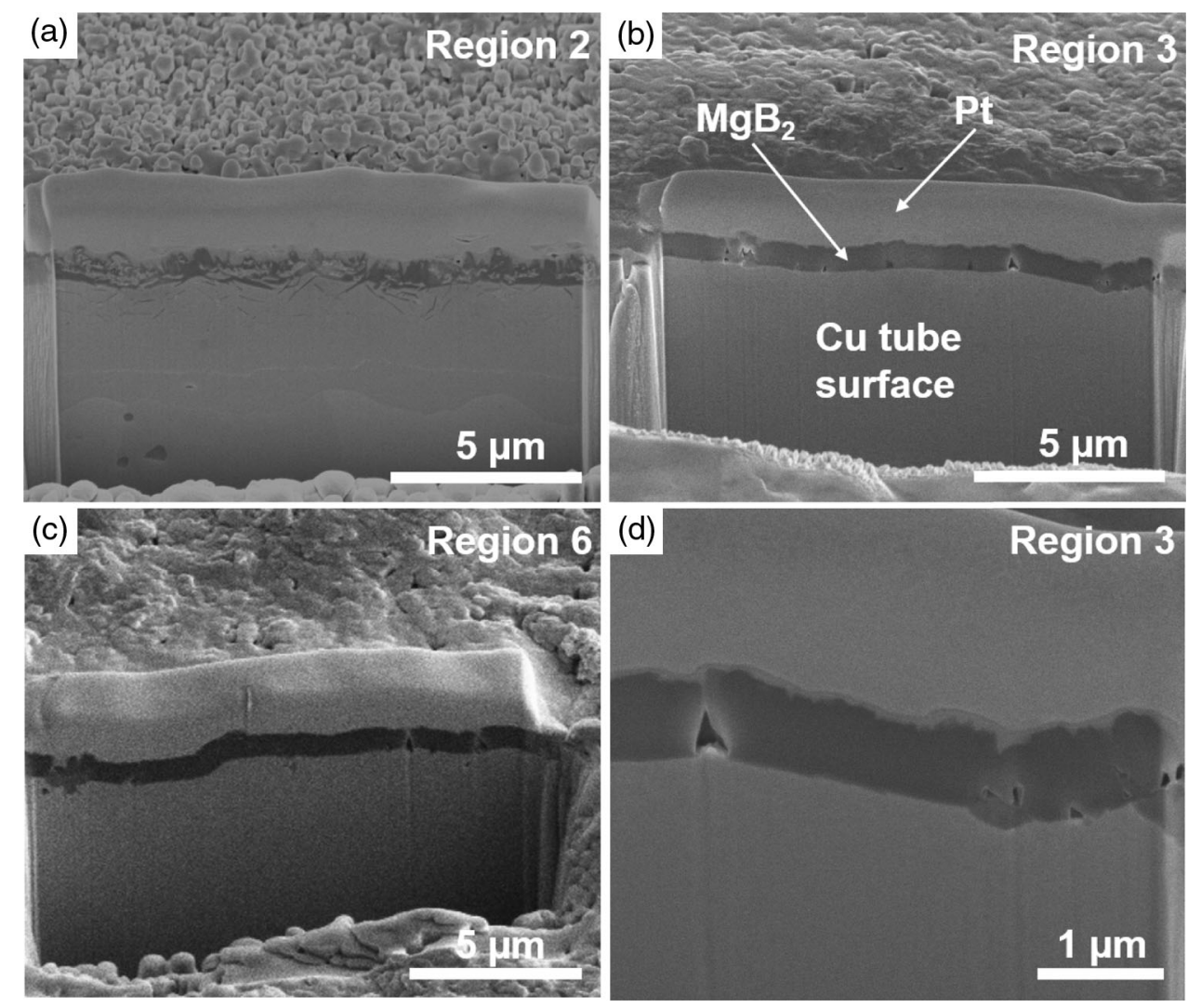

FIG. 5. (a)-(c) Cross section images of samples cut out from regions 2, 3 and 6, respectively, of a $\sim 850 \mathrm{~nm}$ thick MgB 2 coated tube. (d) Zoomed in cross section image from region 3. 


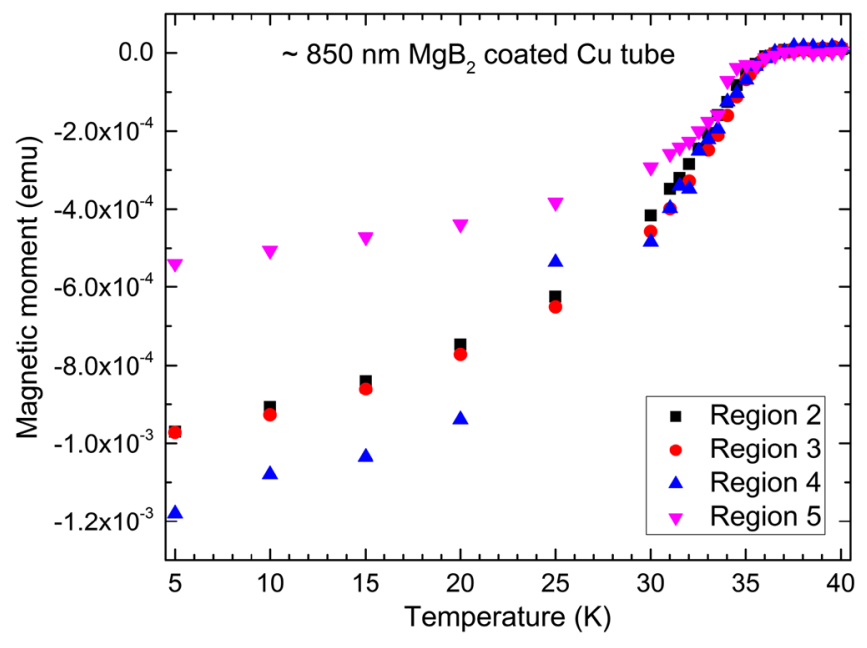

FIG. 6. Magnetic moment vs temperature curves of samples from regions 2, 3, 4 and 5 of a $\sim 850 \mathrm{~nm}$ thick $\mathrm{MgB}_{2}$ coated $\mathrm{Cu}$ tube.

were irregularly shaped, therefore the magnetic moment values cannot be directly compared, including those in Fig. 3.

\section{CONCLUSIONS}

The results presented here demonstrate that uniform $\mathrm{MgB}_{2}$ coating with good superconducting properties can be achieved on the inner wall of commercially available copper tubes. The $\mathrm{Cu}$ tubes were not oxygen free, thus the outgassing of oxygen may have had detrimental effects on the film properties shown here. This can be alleviated by using oxygen-free copper in future studies. The $\mathrm{Cu}$ tubes were not polished, and we show that this may be linked to cracks in thinner films. Preliminary results with polished oxygen-free small $\mathrm{Cu}$ disks attached to a $\mathrm{Cu}$ tube of the same dimensions as in this work show that the $\mathrm{MgB}_{2}$ coatings have much smoother surfaces and more complete superconducting transitions in the $m$ vs $T$ curves than the results presented here. While the cracking problem can be solved by using polished $\mathrm{Cu}$ tubes in the future, we note that cracks can be sealed in thicker films. Thus, a sufficiently thick $\mathrm{MgB}_{2}$ coating may be a solution to the possible cracking due to the mismatch in thermal expansion coefficients between $\mathrm{MgB}_{2}$ and $\mathrm{Cu}$. A remaining issue is the variation of the structure and superconducting properties along the tube axis from one end to the other. The poor coating at either end can be avoided by adding extension tubes at both ends so that only the region with good properties covers the tube or cavity to be coated. The possible variation of deposition temperature with the $Z$ position can be compensated by adjusting the tubular heater temperature while the tube is moving up.

We have successfully coated $\mathrm{MgB}_{2}$ films on the inner wall of unpolished copper tubes using the HPCVD method. The $\mathrm{MgB}_{2}$ coatings showed $T_{c}$ around $37 \mathrm{~K}$ over a seven-inch length. A large portion of the coated tube showed dense and uniform coating free from cracks when the thickness of the film was around $\sim 850 \mathrm{~nm}$. The cracks, which were observed in the thinner $\sim 550 \mathrm{~nm}$ film, seem to be sealed by the top $\mathrm{MgB}_{2}$ layer. The results show the feasibility of using the HPCVD method to coat $\mathrm{MgB}_{2}$ on the inner wall of $\mathrm{Cu}$ cavities.

\section{ACKNOWLEDGMENTS}

This work was supported by the U.S. Department of Energy, Office of Science under the Contract No. DEAC02-06CHI 1357. This work also made use of the College of Engineering-Nano Instrumentation Center at Temple University. College of Engineering-Nano Instrumentation Center is based on Department of Defense-Defense University Research Instrumentation Program Grant No. N0014-12-1-0777 from the Office of Naval Research and is sponsored by the College of Engineering, Temple University.

[1] G. Ciovati, Where next with SRF?, in Proceedings of the 4th International Particle Accelerator Conference, IPAC2013, Shanghai, China, 2013 (JACoW, Shanghai, China, 2013).

[2] J. Nagamatsu, N. Nakagawa, T. Muranaka, Y. Zenitani, and J. Akimitsu, Superconductivity at $39 \mathrm{~K}$ in magnesium diboride, Nature (London) 410, 63 (2001).

[3] X.X. Xi et al., MgB 2 thin films by hybrid physicalchemical vapor deposition, Physica (Amsterdam) 456C, 22 (2007).

[4] T. Tajima, Possibility of $\mathrm{MgB}_{2}$ application to superconducting cavities, in Proceedings of the 8th European Particle Accelerator Conference, Paris, 2002 (EPS-IGA and CERN, Geneva, 2002).

[5] C. Buzea and T. Yamashita, Review of the superconducting properties of $\mathrm{MgB}_{2}$, Supercond. Sci. Technol. 14, R115 (2001).

[6] E. W. Collings, M. D. Sumption, and T. Tajima, Magnesium diboride superconducting RF resonant cavities for high energy particle acceleration, Supercond. Sci. Technol. 17, S595 (2004).

[7] H. Padamsee, J. Knobloch, and T. Hays, RF Superconductivity for Accelerators, 2nd ed. (Wiley-VCH Verlag GmbH \& Co., Morlenbach, Germany, 2008).

[8] W. K. Withanage, X. X. Xi, A. Nassiri, N. Lee, M. A. Wolak, T. Tan, P. B. Welander, M. Franzi, S. Tantawi, and R. L. Kustom, Growth of magnesium diboride films on 2 inch diameter copper discs by hybrid physical-chemical vapor deposition, Supercond. Sci. Technol. 30, 045001 (2017).

[9] Y. Hishinuma, A. Kikuchi, Y. Iijima, Y. Yoshida, T. Takeuchi, and A. Nishimura, Superconducting Properties of $\mathrm{Mg}_{2} \mathrm{Cu}$-Doped $\mathrm{MgB}_{2}$ Wires With Several Metal Sheath for Fusion Reactor Application, IEEE Trans. Appl. Supercond. 17, 2798 (2007). 
[10] A. Kikuchi, Y. Yoshida, Y. Iijima, N. Banno, T. Takeuchi, and $\mathrm{K}$. Inoue, The synthesis of $\mathrm{MgB}_{2}$ superconductor using $\mathrm{Mg}_{2} \mathrm{Cu}$ as a starting material, Supercond. Sci. Technol. 17, 781 (2004).

[11] N. Lee, W. K. Withanage, T. Tan, M. A. Wolak, A. Nassiri, and X. X. Xi, Hybrid physical chemical vapor deposition of magnesium diboride inside $3.9 \mathrm{GHz}$ mock cavities, IEEE Trans. Appl. Supercond. 27, 3500304 (2017).
[12] M. A. Wolak, T. Tan, A. Krick, E. Johnson, M. Hambe, K. Chen, and X. X. Xi, Superconducting magnesium diboride coatings for radio frequency cavities fabricated by hybrid physical-chemical vapor deposition, Phys. Rev. ST Accel. Beams 17, 012001 (2014).

[13] J. D. Jorgensen, D. G. Hinks, and S. Short, Lattice properties of $\mathrm{MgB}_{2}$ versus temperature and pressure, Phys. Rev. B 63, 224522 (2001). 